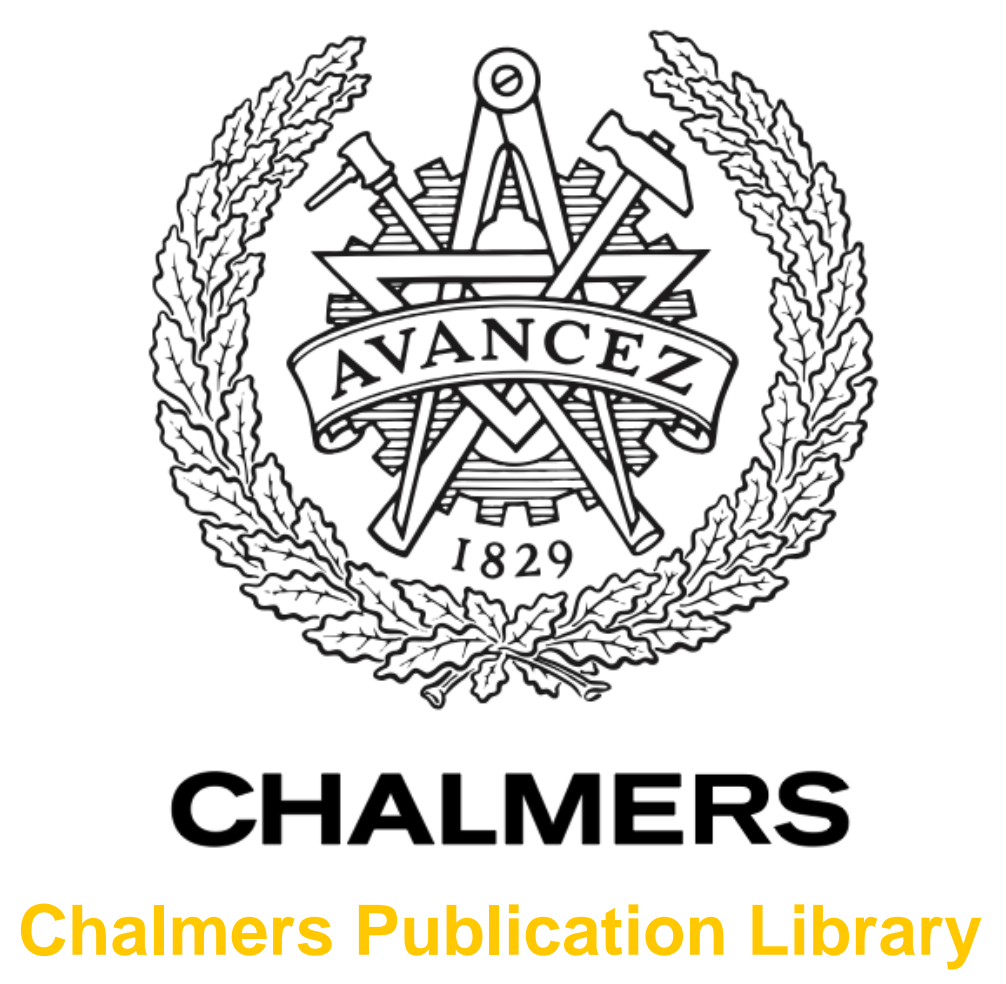

\title{
Adopting new ways of working in small and medium-sized enterprises: findings from interventions in 12 European companies
}

This document has been downloaded from Chalmers Publication Library (CPL). It is the author's version of a work that was accepted for publication in:

Total Quality Management and Business Excellence (ISSN: 1478-3363)

\begin{abstract}
Citation for the published paper:
Assarlind, M. ; Eriksson, H. ; Gremyr, I. (2013) "Adopting new ways of working in small and medium-sized enterprises: findings from interventions in 12 European companies". Total Quality Management and Business Excellence
\end{abstract}

http://dx.doi.org/10.1080/14783363.2013.791108

Downloaded from: http://publications.lib.chalmers.se/publication/179066

Notice: Changes introduced as a result of publishing processes such as copy-editing and formatting may not be reflected in this document. For a definitive version of this work, please refer to the published source. Please note that access to the published version might require a subscription. 


\title{
Adopting New Ways of Working in SMEs: Findings from Interventions in twelve European Companies
}

\author{
Marcus Assarlind*, Henrik Eriksson, Ida Gremyr, Torbjörn Jakobsson \\ Division of Quality Sciences, Chalmers University of Technology \\ *marcus.assarlind@chalmers.se
}

This is an Author's Original Manuscript of an article whose final and definitive form, the Version of Record, has been published in the Total Quality Management \& Business Excellence journal 13 May 2013 [copyright Taylor \& Francis], available online at:

http://www.tandfonline.com/doi/abs/10.1080/14783363.2013.791108.

\begin{abstract}
This paper elaborates on factors to consider in order for interventions (activities aimed at introducing new ways of working through a series of focused activities in an organisation) to lead to long-term effects inside SMEs. The purpose of it is to describe how interventions can be carried out in order for small and medium-sized companies (SMEs) to adopt new ways of working by understanding the context, process and content of an intervention. The results of this study suggest that in designing interventions for the SMEs, the context aspects of an intervention must be carefully considered. Not only is the process or context of an intervention important, but so is the content. As a consequence, we suggest content that accomplishes the following: 1) supports the formulation of strategies; 2) encourages dialogue; and 3) uses company data. The paper is based on a multiple case study of twelve SMEs from six European countries undergoing similar interventions within the FutureSME project. These long-term relationships within a largescale project have provided access and a rare opportunity to conduct research on this often overlooked business sector. The empirical data has been collected through company presentations, structured reports, and narratives. The material has been subject to a cross-case analysis.
\end{abstract}

Keywords: interventions, self-assessment, business diagnostic, visual strategy, strategy wall, SME

\section{Introduction}

There have been thorough descriptions of specific improvement initiatives, such as Lean manufacturing (Liker, 2004; Spear \& Bowen, 1999) and Six Sigma (Jones, Parast, \& Adams, 2010; Schroeder, Linderman, Liedtke, \& Choo, 2008). A few of these descriptions address Small and Medium-Sized Enterprises (SME) in particular (e.g. Achanga, Shehab, Roy, \& Nelder, 2006; Garengo \& Biazzo, 2012; Kumar, Antony, \& Tiwari, 2011; Prajogo \& Brown, 2006), but this focus is uncommon. Such special consideration of SMEs is nevertheless motivated by specific needs in comparison to large organisations, and the major improvement initiatives have been developed for large companies (Yusof \& Aspinwall, 2000b). One common way for SMEs to get into contact with new ways of working is through some type of external intervention. However, 
SMEs have been found less likely to succeed in adopting new ways of working as a result of interventions (Shah \& Ward, 2003). Done, Voss, and Rytter (2011, p. 510) summarise the main issue as "the combination of a lack of initial capability, often difficult contexts, limited time and scarce resources makes long-term BPI [best practice intervention] success very difficult to achieve in SMEs". Inspired by Done et al. (2011), an intervention is in this paper defined as activities aimed at introducing new ways of working through a series of focused activities in an organization.

Regarding interventions and their role in affecting change, By (2005) points to the need for identifying additional success factors in order to learn more about interventions. To improve the chances that an intervention results in long-term effects in SMEs, Done et al. (2011) identified eleven propositions driving successful outcomes. These propositions or factors are mainly concerned with how an intervention should be carried out and to some extent desirable characteristics of an SME, such as readiness for change. Drawing on Pettigrew's (1987) contextcontent-process model for organisational change, these factors relate to the process and to some extent the context of an intervention. Pettigrew's (1987) model suggests the necessity of also looking at the content of change. The purpose of this paper is to describe how interventions can be carried out in order for SMEs to adopt new ways of working by understanding the context, process and content of an intervention.

The paper is based on a study of twelve SMEs participating in FutureSME - a four-year FP7 research project comprising 26 partners (SME managers, researchers and consultants) aiming at improving the competitiveness of European SMEs. Within the project, the SMEs have been subject to interventions in the form of at least two activities; the use of a self-assessment tool (referred to as the "Business Diagnostic") and a visual tool for strategy formulation (referred to as the "Strategy Wall"). Following these activities, the companies have tried new ways of working in a variety of areas depending on specific company needs. Before describing the research method in more detail, the theoretical framework is presented. The remaining parts of the paper report empirical results, discusses the subject and arrives at a conclusion.

\section{Theoretical framework}

Change can be viewed from a range of perspectives, for example by the planned approach or the emergent approach, with the latter gaining ground (Burnes, 1996; By, 2005). However, these approaches do not need to be conflicting, but may rather be complementary and applicable in different contexts (Burnes, 1996). In stable environments, the planned approach has proven effective (Burnes, 1996), while today's rapidly changing external environment gives merit to the emergent approach (Bamford \& Forrester, 2003). By (2005) describes the emergent approach as perceiving change taking place from the bottom up. While in the planned approach change is seen as a series of linear events within a given time frame, in the emergent approach, change is seen as a continuous, open-ended process of adaptations to changing circumstances and conditions.

Another classification of change is put forward by Beer and Nohria (2000) who suggest that change can be explained by two theories, Theory E and Theory O. Regarding the process dimension of change, Theory $\mathrm{E}$ is about planning and establishing programs, while the process dimension in Theory $\mathrm{O}$ rather concerns experimenting and evolving. However, the same authors argue that any one of these directions is seldom optimal but that a sensible combination would 
often be the most effective way to bring about improvements. The argumentation of Hargadon and Eisenhardt (2000) is similar and in the context of product development, they suggest there is a need to balance planning and learning, as well as making decisions and expressing doubts. This perspective would require new roles of management that would emphasize "shaping" over "controlling" (Palmer, Dunford, \& Akin, 2009).

As previously argued, SMEs are generally not in a position to only replicate approaches from larger companies (Yusof \& Aspinwall, 2000a). Oakland and Tanner (2007) claim that almost all drives towards major change are triggered by external events, with Pettigrew (1987, p. 657) stating that "formulating the content of any new strategy inevitably entails managing its context and process". In Pettigrew's context-content-process model on change, there is an outer context that includes social and environmental factors, as well as an inner context encompassing structure, culture and company politics. The reason for change and legitimacy for change, according to Pettigrew (1987), primarily emanates from the outer context. Furthermore, the process includes actions, reactions and interactions by and between different stakeholders. Hence, this framework can be used to analyse the 'why', the 'what', and the 'how' of a change process.

While individual SMEs are impacted by their own contexts, for example different company cultures or operating in different sectors with special regulations (Ghobadian \& Gallear, 1997; Hansson \& Klefsjö, 2003), there are also factors that are often mentioned as distinguishing for SMEs as a group. Two of the most common examples are flat hierarchies with quick information exchange and a scarcity of resources (e.g. Rahman \& Tannock, 2005; Yusof \& Aspinwall, 2000a). The SME lack of resources does not only manifest itself through the absence or paucity of investable cash, it also surfaces as a scarcity of internal change agents who possess knowledge on best practices and know-how on change processes. One way of solving this problem is through external interventions as a means of supporting change.

Kotter (1995) and Oakland and Tanner (2007) are examples of authors who propose success factors for change in general; Done et al. (2011) propose a similar set of factors but address best practice interventions (BPI) applicable to SMEs. Done et al. (2011) see two main difficulties facing interventions in SMEs; first, it can be questioned whether or not a one-off intervention can create sustainable change in the practices of a company. Second, there exists a conflict between short and long-term objectives, in which the focus on short-term effects may lead to absence of long-term effects. At the same time, short-term effects play a role in motivating continuous efforts towards long-term effects. Done et al. (2011) propose and explore a framework of eleven propositions (grouped into "Intervention context", "Intervention design and implementation", and "Change-agent approach") that influence the short-term success and long-term sustainability of BPIs.

One way to understand change is by using the analytical framework suggested by Pettigrew (1987) and focusing on context, content, and process dimensions. Even if one could argue that Pettigrew's view represents the emergent school, his analytical framework may be used in studying any type of organisational change. One could propose that the work by Done et al. (2011) and their propositions for successful BPIs might represent a prescribed and planned view on change. However, intervention does not by necessity imply a prescribed view on the complete change process. We argue that interventions also play a key role in emergent changes provided they are shaped appropriately. The conceptual model of this paper is displayed in Table I, which positions the propositions devised by Done et al. (2011) into Pettigrew's (1987) analytical 
framework (context-content-process). The model is hence a way of further understanding how interventions can be shaped in a way that accounts for all dimensions in Pettigrew's framework. In doing this, it becomes apparent that the propositions put forth by Done et al. (2011) are mainly related to the context and process dimensions.

Table I: Propositions for short-term success and long-term sustainability of BPIs (Done et al., 2011) related to Pettigrew's (1987) dimensions of change

\begin{tabular}{|c|c|c|c|}
\hline Proposition & Context & Content & Process \\
\hline \multicolumn{4}{|l|}{ Intervention context } \\
\hline Clearly communicated strategy and objectives for change & $\mathrm{x}$ & & \\
\hline Organisational readiness for change & $x$ & & \\
\hline KPIs aligned to programme of change objectives & $\mathrm{x}$ & & \\
\hline Reward and recognition of positive short-term results & $x$ & & \\
\hline Intervention design and implementation & & & \\
\hline Tailoring BPI format to specific context & & & $\mathrm{x}$ \\
\hline Organisation and provision of resources & & & $\mathrm{x}$ \\
\hline Well-managed implementation & & & $\mathrm{x}$ \\
\hline Stakeholder management & & & $\mathrm{x}$ \\
\hline Development of internal facilitator/champions & & & $x$ \\
\hline Change-agent approach & & & \\
\hline Change agent overall knowledge and competence & & & $\mathrm{x}$ \\
\hline Post-BPI planning for ongoing activities and consultant support & & & $\mathrm{x}$ \\
\hline
\end{tabular}

To make substantial progress in a company's work practices, it is vital to have a strategy for the adoption of new practices (Upton, 1996; Yusof \& Aspinwall, 2000a). However, while the literature often views strategy as a formalised top-down process, SMEs often consider it as emerging, if at all (Garengo \& Biazzo, 2012). Yusof and Aspinwall (2000a, p. 33) offer a conceptual framework to implement quality management in SMEs, including a step-wise approach to outline a strategy for the adoption of new concepts in SMEs: 1) the creation of a coordinating body; 2) the development of a vision, mission and policy statements; 3) the education of top management and coordinating body members on total quality principles and philosophy; 4) the selection and trial run of the first improvement project; and 5) the appraisal of a company's current level. All steps outlined would in the context-content-process mode (Pettigrew, 1987) be part of the process dimension. However, seen from a BPI perspective, the method of formulating a strategy can also be viewed as part of the content.

A common and practical way to start an intervention is by mapping where a company stands today, its strengths and weakness, thus performing a self-assessment of a firm (Finn \& Porter, 1994; van der Wiele et al., 1996). van der Wiele et al. (1996) claim that self-assessments not only aid in identifying strengths and weaknesses, but also contribute to learning in terms of transferring best practices and ideas. It may be problematic for SMEs to use self-assessments as these assessments are often developed with large organisations in mind. After studying seven SMEs, Wilkes and Dale (1998) conclude that SMEs often lack recourse, time and/or knowledge to perform self-assessments, and that a simplified assessment is most often needed. Hellsten (1997) indicates that in order to support SME use of self-assessments, more attention should be given to the manner in which the work is carried out; the process of self-assessment per se. Furthermore, Eriksson (2003) argues that limited attention is given to the planning and execution of the actual improvements identified through an assessment. 


\section{Method}

This paper sets out to describe how interventions may be carried out. According to Dane (1990), descriptive research involves examining a phenomenon to define it more fully or to differentiate it from other phenomena. The examination of a contemporary phenomenon in a specific context, such as this study on interventions in SMEs, is well-suited for case study research (Dubois \& Gadde, 2002; Eisenhardt, 1989). This paper is, accordingly, based on a multiple case study of twelve companies (see Table II).

Table II: Overview of companies, including country, number of employees, and type of business

\begin{tabular}{|l|l|l|l|}
\hline Company & Country & $\begin{array}{l}\text { Number of } \\
\text { employees }\end{array}$ & Type of business \\
\hline Tracking Ltd & Czech Republic & 65 & Manufacturing, tracking devices \\
\hline Automation Ltd & Czech Republic & 71 & Engineering, automation \\
\hline Pallets Ltd & Ireland & 300 & Manufacturing, pallet components \\
\hline Machinery Ltd & Ireland & 6 & Manufacturing, machinery \\
\hline Cloths Ltd & Italy & $<20$ & Manufacturing, cloth prototyping \\
\hline Aircrafts Ltd & Italy & 20 & Development and manufacturing, unmanned aircraft \\
\hline Ink Ltd & Poland & 160 & Manufacturing, ink cartridges \\
\hline Bottling Ltd & Scotland & 64 & Manufacturing, beverage bottling \\
\hline HiFi Ltd & Scotland & 160 & Development and manufacturing, HiFi equipment \\
\hline Plastic Ltd & Turkey & 79 & Manufacturing, plastic products \\
\hline Cabling Ltd & Turkey & 250 & Manufacturing, electromechanical products \\
\hline Refrigeration Ltd & Turkey & 246 & Manufacturing, refrigeration appliances \\
\hline
\end{tabular}

${ }^{1}$ Actual company names are replaced by fictitious names.

${ }^{2}$ Type of business represents core activities.

The twelve companies have been partners in the FutureSME research project and have been subject to interventions as well as other project activities, such as seminars and project meetings, over a period of four years. Major events have included seven partner meetings of two days each. These meetings have involved all projects partners: company representatives as well as consultants and research partners, including the authors of this paper. Further, there have been a number of continuous monthly on-line meetings of different constellations during which design and implementation of interventions, as well as company progress and difficulties, have been discussed.

Each company has undergone an intervention of at least two pre-defined activities (the so- called "Business Diagnostic" and "Strategy Wall") facilitated by an external facilitator from each country. For this paper, a number of different company data has been used: most prominently information from "meetings", "A3 reports" and "case essays". At semi-annual meetings, the outcome and experiences of the interventions have been tracked. At the two most recent meetings, there have been formal presentations by company representatives supported by external facilitators. A3 reports include structured information on these interventions. Drafts of these reports were compiled by the authors of this article based on previous project information and were subsequently complemented, refined and validated by the companies and their external facilitators in an iterative process aided by the authors. The case essays in turn include subjective descriptions of the experiences over the past four years for each respective company. This approach allows for triangulation in terms of different data sources, allowing for increased depth and consistency (Flick, 2006). Evidently, the bulk of data is made up of solicited documents 
(Flick, 2006) by a number of different people, national facilitators and managers across a range of different cultures. This has naturally affected the style of the different documents, most notably the balance between positive and negative features, an aspect that was considered during the qualitative analysis.

The data has since been subject to a cross-case analysis, in which a number of empirically based patterns was compared to the predicted pattern derived from theory; referred to as "pattern matching" by Yin (1994). The predicted pattern that this study sets out to illuminate is the propositions for BPI in SMEs suggested by Done et al. (2011). Hence, data from the cases have been analysed and understood with the use of these propositions. Further, similarities and differences between the cases and the framework proposed by Done et al. (2011) are discussed from the perspective of Pettigrew's (1987) context-content-process model.

\section{Results}

The section detailing results is divided into two parts: the first introduces the FutureSME project, while the second divulges the context, content and process of the interventions.

\section{$4.1 \quad$ FutureSME}

FutureSME is an $€ 8$ million project funded by the EU 7th Framework Programme. The project consortium of 26 partners includes 13 manufacturing SMEs, research and development organisations, consultancy companies, as well as SME support agencies. The FutureSME project aims at improving the competitive capabilities of SMEs. The key capabilities may be summarised as: Managerial, Strategic, Operational, and Adaptive capability. Within the project, a so-called "transformation process" is recommended to support capability development. This process is built on the idea of enabling an organisation to learn by thinking, acting and reflecting together in an open and inclusive working environment. The core capabilities are enhanced by repeating the transformation cycle on an on-going basis. The basis of this transformation process is described by the project as: "the systematic use of the diagnostic, visual strategy and visual management tools that enables the organisation to refine its direction, identify opportunities, set priorities, formulate and deliver innovative responses that lead to sustainable business - in effect enabling them to become an adaptive organisation".

In this paper a substantial emphasis is placed on two activities that have occurred in all SME interventions: Business Diagnostic (BD) and Strategy Wall (SW), both to be performed with the top management team in a four-hour-session each. The BD is a diagnostic tool consisting of 130 questions, covering ten areas (eight key business areas and two contextual). The BD output is a report that shows priority areas for improvement, analysis of the key business areas and references to support tools on the FutureSME webpage. The SW is a tool to establish and visualise a strategy. Its aim is to break down the strategy of the organisation into an easy-tounderstand and editable visual board (e.g. using a whiteboard). The tool consists of five steps: statement of the vision, mission and values, scanning for changes in the external environment, conduct of an internal analysis, performance of a SWOT analysis, and finally, drawing up a strategy map on which the overall strategic goals are broken down into tangible goals/projects. The final output is a two-by-two matrix visualising the strategy of the organisation. 


\subsection{The Context, Content and Process of the Interventions}

The SMEs participating in the project have been involved in a number of activities as well as project meetings. The BD and SW have been performed on all companies that are part of the project. Apart from the foregoing, there has been a variety of other activities in the participating companies; see Table III which provides a summary of the intervention activities along with the major outcomes.

Table III: Main activities performed and major outcomes of the different cases within the project. The following abbreviations are used: $Q D=Q u i c k$ Diagnostic, BD=Business Diagnostic, SW=Strategy Wall and $K P I=$ Key Performance Indicators

\begin{tabular}{|c|c|c|}
\hline Company & Activities & Self-Reported Outcomes \\
\hline Tracking Ltd & $\begin{array}{l}\text { QD, BD, SW, Micropayment } \\
\text { system }\end{array}$ & $\begin{array}{l}\text { Dividing the company into two divisions. The introduction of a } \\
\text { micropayment system that decreased administration costs by } \\
30 \% \text {. General increase in turnover and employees. }\end{array}$ \\
\hline Automation Ltd & $\mathrm{QD}, \mathrm{BD}, \mathrm{SW}, \mathrm{KPI}$ review system & $\begin{array}{l}\text { A new IT system collected all company data into one database } \\
\text { freeing up } 20 \% \text { more time for management and senior employees } \\
\text { to be spent on training. A new training facility was constructed. }\end{array}$ \\
\hline Pallets Ltd & $\begin{array}{l}\text { QD, BD, SW, KPI dashboard, } \\
\text { Capability development } \\
\text { programme (CDP) }\end{array}$ & The KPI dashboard provided an improved management structure. \\
\hline Machinery Ltd & $\begin{array}{l}\text { QD, BD, SW, CDP, Corporate } \\
\text { Social Responsibility, Design } \\
\text { for the Environment, Produce } \\
\text { Supply Service, Lean }\end{array}$ & $\begin{array}{l}\text { Major overall reconstruction of the company. The company was } \\
\text { substantially affected by the economic recession but has since } \\
\text { seen improvement in their business on several levels. }\end{array}$ \\
\hline Cloths Ltd & $\begin{array}{l}\text { QD, BD, SW, Kanban system, } \\
\text { New production planning }\end{array}$ & $\begin{array}{l}\text { Lead times reduced by } 25 \% \text {. Production planning time reduced by } \\
60 \% \text {. Production moved from a push to a pull system. A visual } \\
\text { management system has been beneficial in preventing } \\
\text { overbooking and planning subcontracting more efficiently. }\end{array}$ \\
\hline Aircrafts Ltd & $\begin{array}{l}\text { QD, BD, SW, KPI development, } \\
\text { Visual management system, } \\
\text { Affinity and Interrelationship } \\
\text { Methodology }\end{array}$ & $\begin{array}{l}\text { Changing business model and profit formula to fit its business and } \\
\text { business environment. Customer satisfaction was one of the most } \\
\text { important KPI's to have seen improvement. }\end{array}$ \\
\hline Ink Ltd & $\begin{array}{l}\text { QD, BD, SW, A3 reports, Value } \\
\text { stream mapping (VSM), } \\
\text { Introducing PDCA }\end{array}$ & $\begin{array}{l}\text { Major focus on introducing lean methodologies which yielded } \\
\text { decreases in: rework, lead-times, cost/pcs, process times and } \\
\text { production space. It has also led to an increase in productivity. }\end{array}$ \\
\hline Bottling Ltd & $\begin{array}{l}\text { BD, SW, Core capability } \\
\text { development programme, } 5 \mathrm{~S}\end{array}$ & $\begin{array}{l}\text { Creation of a common strategy for the company and, thus, } \\
\text { common objectives that increased the company's ability to stay } \\
\text { competitive. }\end{array}$ \\
\hline HiFi Ltd & $\begin{array}{l}\text { BD, SW, Capability } \\
\text { development programme }\end{array}$ & $\begin{array}{l}\text { Implementation of visual strategy management, creating a solid } \\
\text { basis for continuous improvement of the business. }\end{array}$ \\
\hline Plastic Ltd & $\begin{array}{l}\text { QD, BD, SW, Design for } \\
\text { Environment, energy } \\
\text { efficiency project, Customer } \\
\text { Relationship Management, } \\
\text { Just in time }\end{array}$ & $\begin{array}{l}\text { Conducted a large energy efficiency project that yielded large } \\
\text { cost savings. Introduction of visual strategy management } \\
\text { encouraged coordination and integration between departments } \\
\text { and management team. Greater involvement of the shop floor } \\
\text { staff has given beneficial inputs to the company. }\end{array}$ \\
\hline
\end{tabular}




\begin{tabular}{|l|l|l|}
\hline Cabling Ltd & $\begin{array}{l}\text { QD, BD, SW, Production } \\
\text { Feasibility Check (Sales } \\
\text { Configuration), Innovation } \\
\text { management }\end{array}$ & $\begin{array}{l}\text { A visual strategy methodology made it possible to align } \\
\text { improvement projects with overall business goals. A key benefit } \\
\text { was seeing how projects are linked to goals in the 'Big Picture'. } \\
\text { Reworking how the production feasibility check was handled } \\
\text { decreased feasibility checks by 80\%, which led to a decrease in } \\
\text { lead time and increased competitiveness. }\end{array}$ \\
\hline $\begin{array}{l}\text { Refrigeration } \\
\text { Ltd }\end{array}$ & $\begin{array}{l}\text { QD, BD, SW, Quick Response } \\
\text { Manufacturing, Kaizen }\end{array}$ & $\begin{array}{l}\text { Visual strategy management made it possible for the company to } \\
\text { see the "Big Picture", thus improving its business. A pilot project } \\
\text { for a manufacturing cell according to quick response } \\
\text { manufacturing (QRM) methodologies was successfully } \\
\text { completed. The company will use QRM principles throughout the } \\
\text { company to enable quicker response to market demands. }\end{array}$ \\
\hline
\end{tabular}

In order to understand how the interventions were carried out and how they affected the company, the empirical data has been structured in terms of context, content, and process (Pettigrew, 1987).

\subsubsection{Context}

FutureSME is a project engaging partners from many different countries and cultures. The project language and supporting material for the intervention have been written in English. However, the intervention itself was carried out in local languages. Companies that do not have English as a corporate language seem to have experienced greater difficulties in adopting the ideas and methodologies. There is a need, often addressed by non-English speaking partners, to translate the material into the respective language in order to attain the full benefit of the project. Also, companies that have been geographically closest to the project coordinator have been used as benchmarks, internally and externally to the project.

The purpose established by the companies and the reasons they joined the project were initially not always evident. Several SMEs expressed only general reasons for their participation in the project; the aim was to set a common language of the employees about the functions and actions of the company itself. Others foresaw more specific outcomes such as the expectation that FutureSME will give us the techniques, which will enable us to get an objective evaluation of the company situation in different areas. However, for some companies the need to establish goals and visions became clear only after having performed the BD, something that was vividly stated by one of the participants: one of our company's weak points was to combine the projects and activities with the main goals and vision. Going through the visual strategy methodology [SW], the management team was able to align improvements projects with the main business goals in a Strategy Map.

\subsubsection{Content}

Comparing two of the main tools used in this project, the SW appears easier to adopt than the $\mathrm{BD}$, possibly because of the more open and flexible approach that may easily be adapted to fit a specific context. Further, the output of the Strategy Wall is visible which makes it easier to comprehend and take actions on these findings. As stated by a participant, having the visual strategy boards so accessible to the management team provided a constant reminder of the business vision and strategy, and prompted a review of the actions at each meeting. 
The fact that SW was perceived as being more beneficial than BD may also be attributed to the fact that the latter is a computerised methodology, which does not offer the same involvement among practitioners. For example, practitioners fill out an assessment and receive an automatically regenerated report. The step from input data to report is perceived as a black box in which the output is not tailored to the specific company. Sometimes, users even felt that the report was not aligned to the answers they had given in the assessment. The SW, on the other hand, was built solely on the involvement of practitioners in each step of the process.

The improvement evident in the cases is often based on actions or projects that have followed an actual intervention. Thus, it seems as though an internal intermediate "step" was needed to connect the output of BD and SW interventions to something concrete for the company. Based on the data, it is difficult to conclude if these outcomes are derived from the interventions or from other factors that would have happened anyway. It appears, however, that concrete company projects may convey results from the BD and SW. In other words, specific company projects build on results from $\mathrm{BD}$ and $\mathrm{SW}$, thus connecting them to daily operations. It is noteworthy that the intermediate step and projects following the interventions are not facilitated by an external facilitator.

Another output of the interventions relates to companies establishing different forums for continuous work and follow-up. For example, to sustain the improvements and to establish a continuous improvement culture in the organization, the management team has set up regular meetings to review goals and plans. Other similar outcomes that reveal the need for continuous follow-up include the Business Diagnostics will be run each six month to keep the changes of our company's overall performance visible. The repeated use of the same tool within FutureSME has been viewed as beneficial and it has been advised that both BD and SW should be executed on a number of different occasions. This has been perceived as beneficial - thanks to all these tests and exercises, our mental approach has evolved, although not concerning the whole company, but certainly within the management team.

\subsubsection{Process}

Looking at what has been accomplished in the SMEs, it is evident that the external facilitator has played an important role. Depending on the expertise of the external facilitator, the companies have taken different routes and actions. Thus, the outcome appears dependent on the personality and knowledge of the facilitator. As an example, the main outcome reported by Ink ltd, which mostly worked with a facilitator with extensive knowledge of Lean manufacturing, was stated as: initiation of implementation of lean manufacturing tools. The key outcomes of this were among other shortening of lead times; rework reduction, growth in number of problem solved, and process standardization. Another company had a facilitator working with environmental issues, stating that the key outcome of this was the start of a successful project aimed at reducing electricity consumption in the factory and thus reducing the production costs.

BD and SW are both team based and involves staff besides the manager or owner, something that was reported to have consequences for ways of working and how responsibility was delegated throughout the organisation. An example concerning the BD: result can also be seen in that some authority was delegated from the managing director, from one person, to a wider management team, and the change is seen to be positive. However, new ways of working was also challenging, when a company started to involve several employees in strategy formulation who later felt that they were unable to cope with the diversity of points of view which led to a situation 
when employees started to resign from participating in this type of work. However, although the company experienced staff withdrawing from the improvement work, they stated that one positive thing was that we found 3-4 employees who have a comprehensive strategic view point and these people are now being heard by the top managers.

\section{Analysis}

In this section, empirical findings from cases are contrasted against the eleven propositions for best practice interventions (BPI) in SMEs, as suggested by Done et al. (2011), thereby matching case results as well as suggesting how their framework may be expanded.

\subsection{Matching case results with propositions}

Done et al. (2011) cluster the first propositions relating to the intervention context, starting off with the need for "clearly communicated strategy and objectives for change". This has varied along the cases studied, but a general note is that specific company goals for undertaking the intervention have evolved gradually during the project. The cases presented had different incentives for taking part in the FutureSME project, but an overall "organisational readiness to change" has not been assessed in a structured way, although the mere participation in this type of research project could be an indication of an interest in developing, or changing, the business. The proposition "KPIs aligned to programme of change objectives" was not elaborated on the outset of the intervention. However, KPIs are part of the content of the SW and thus rather an anticipated outcome of the intervention. The final driver related to the intervention context "Reward and recognition of positive short-term results" - has not been elaborated on in the interventions although the SMEs informally showing beneficial results were often acknowledged and used as benchmarks during partner meetings.

Intervention design and implementation is the second cluster of factors of Done et al. (2011), starting off with "Tailoring BPI format to specific context". This was partly achieved through the long-term relationship between the external facilitator and the company, making it possible for the facilitator to modify the intervention to suit the specific SME. Moreover, throughout the project, facilitators and practitioners were funded by the project. Hence, there were resources allocated to work with the intervention, in other words the "organisation and provision of resources" were acknowledged. A "well-managed implementation" depended on the specific company and external facilitator, and consequently, the difference between a well managed and a poorly managed implementation could be recognised. The proposition "stakeholder management" involves paying attention to the needs of different groups and functions, such as senior and middle management and employees. In many cases, senior management has been deeply involved in the intervention, as well as having participated in project meetings. The proposition "development of internal facilitator/champions" has to some extent been taken care of since contact persons at each company have taken part of the network and meetings and been given the opportunity to learn from other SMEs, as well as researchers and consultants.

Finally, Done et al. (2011) argue that factors related to the "Change-agent approach" are important, citing the "change agent and its overall knowledge and competence". In this study, the external facilitator acted as a change agent and SME progress was often observed in the areas where the facilitator has his/her expertise. Finally the proposition, "Post-BPI planning for ongoing activities and consultant support", was gradually considered. The cases reported that a number of ongoing projects, systematic activities and follow-ups were in place after the 
intervention. The external facilitator did not by and large assume responsibility to drive or even take part in those activities.

In summary, the process aspects have been well prioritised in the FutureSME project. However, our data suggests a deficiency in the context aspects of the interventions of the project. This may be troubling since much of the legitimacy for change is said to come from the outer context (Pettigrew, 1987), and that a lack of focus on the context of the intervention may prevent short term improvement and sustainable change (Done et al., 2011).

\subsection{Extending propositions based on case results}

Positioning the propositions proposed by Done et al. (2011) to Pettigrew (1987) framework shows that propositions related to the content are not directly present. Propositions such as "clearly communicated strategy and objectives to change" and "tailoring the BPI format to the specific context" stress the importance of change. However, if left without activities to support them, such propositions risk ending up as empty phrases, especially in SMEs which do not necessarily possess any formulated strategy. Thus, for short-term success and long-term sustainability, there is a direct need for content ensuring proper strategies and goals. In this project, the BD and SW activities help in formulating strategies and objectives for change, as well as paving the way for consecutive activities tailored to specific contexts. We propose, therefore, that "Content that supports the formulation of strategies" be added to the proposition model for interventions in SMEs suggested by Done et al. (2011).

Both the $\mathrm{BD}$ and the $\mathrm{SW}$ require active involvement, and use data, from the company; in contrast to interventions based on presentations of conceptual models or cases from other companies. The findings suggest that when company data is used, the facilitator needs to understand the views of the managers and the data of the specific company, not the other way around (company managers needing to understand the examples and views of the facilitators). SME managers in our cases stress the benefit of discussing problems and opportunities specific to their company. Accordingly, we propose that "Content that uses company data" is added to the propositions compiled by Done et al. (2011).

Furthermore, both the BD and SW activities encourage dialogue among the managers of the company. While the BD provides numbers and performance figures, the most cited advantage are the discussions that emerge among key individuals around critical issues in their company. Similarly, in producing the visual strategy, equally vital issues are discussed. Both activities encourage communicating around the business and reaching consensus, which in turn is a major contributor according to managers participating in the project. Therefore, we suggest "Content that encourages dialogue" to be added to the proposition model by Done et al. (2011).

\section{Discussion}

This paper on designing interventions in SMEs departs from the conceptual model by Done et al. (2011) which is suggesting propositions for successful BPIs in SMEs. This model is in turn related to the analytical framework for change previously proposed by Pettigrew (1987) and does not explicitly address the content dimension. In this multiple case study, we identify the need for propositions that allow for interventions to be shaped to support emergent changes adapted to specific business contexts. This does not mean that the changes need to be fully open ended processes (Burnes, 1996) but can still be intended or partly intended (Palmer et al., 2009) in line 
with the argument to sensibly combine Theories E and O (Beer \& Nohria, 2000). Specifically, we suggest the addition of the following three propositions to describe the content dimension: "Content that supports the formulation of strategies", "Content that encourages dialogue", and "Content that uses company data".

The Business Diagnostics and Strategy Wall are a self-assessment tool and an instrument to support strategy formulation, respectively. Various forms of self-assessments are common in most types of companies, but it has been argued that due to the lack of time, resources and/or knowledge, SMEs might have difficulty in performing assessments developed for large organisations, and hence require simplified assessment tools (Wilkes \& Dale, 1998). The BD is one such simplified tool and has been perceived as quite useful by SMEs in this study. A key to long-term effects is to design internal follow-up activities, or improvement projects, based on the $\mathrm{BD}$ results. The SMEs that acted on the BD results in this way have certainly reported more impact than the SMEs that did not engage in such follow-up activities.

SMEs have often had a hard time rationalising their practices into formalised strategies (Garengo \& Biazzo, 2012). The SW aids directly in the development and formulation of company strategy, as well as in the public display and communication of such strategy before employees and partners. SW is simple, yet potent, in addressing some key aspects of the conceptual framework for implementing quality management offered by Yusof and Aspinwall (2000a). Examples of aspects addressed include appraising a company's current level, and consecutively developing its vision and linking the vision to improvement actions. Advantages of the SW include not only its focus on strategic goals per se, but also a company's vision, mission and values, scanning of changes in the external environment, an internal analysis, a SWOT analysis, and finally, a strategy map on which the overall strategic goals are broken down into more tangible goals/projects. Thus the SW addresses both the inner and outer context (internal analysis and scanning the environment) and the process of change (tangible goals and projects); managing these dimensions has proven necessary in the formulation of any viable company strategy (Pettigrew, 1987, p. 657).

\section{Conclusions}

The purpose of this paper is to describe how interventions may be carried out in order for SMEs to adopt new ways of working by understanding the context, process and content of an intervention. Done et al. (2011) have formulated a framework for successful interventions in SMEs. Based on results from multiple cases, this paper extends this framework by offering three additional propositions related to the content of an intervention: "Content that supports the formulation of strategies", "Content that encourages dialogue", and "Content that uses company data". Our belief is that these propositions contribute to a common understanding among managers of a business in reaching consensus regarding its position and future direction in which the business is going. Consequently, in designing an intervention suitable to SMEs, it may be beneficial for the content to possess these characteristics in order to enhance the possibility of both short-term success and long-term sustainability. 


\section{Acknowledgments}

This research was funded by the European Commission under the $7^{\text {th }}$ Framework Programme with Grant \# CP-IP 214657-2 FutureSME. We extend our sincere thanks to the FutureSME project consortium and partners for their contribution to this paper.

\section{References}

Achanga, P., Shehab, E., Roy, R., \& Nelder, G. (2006). Critical success factors for lean implementation within SMEs. Journal of Manufacturing Technology Management, 17(4), 460-471.

Bamford, D. R., \& Forrester, P. L. (2003). Managing planned and emergent change within an operations management environment. International Journal of Operations \& Production Management, 23(5), 546-564.

Beer, M., \& Nohria, N. (2000). Cracking the Code of Change. Harvard Business Review, 78(3), 133-141.

Burnes, B. (1996). No such thing as ... a "one best way" to manage organizational change. Management Decision, 34(10), 11-18.

By, R. T. (2005). Organisational change management: A critical review. Journal of Change Management, 5(4), 369-380.

Dane, F. C. (1990). Research methods. Pacific Grove, California: Brooks/Cole Publishing Company.

Done, A., Voss, C., \& Rytter, N. G. (2011). Best practice interventions: Short-term impact and long-term outcomes. Journal of Operations Management, 29(5), 500-513.

Dubois, A., \& Gadde, L.-E. (2002). Systematic combining: an abductive approach to case research. Journal of Business Research, 55(7), 553-560.

Eisenhardt, K. M. (1989). Building Theories from Case Study Research. The Academy of Management Review, 14(4), 532-550.

Eriksson, H. (2003). Experiences of working with in-company quality awards: a case study. The TQM Magazine, 15(6), 397-407.

Finn, M., \& Porter, L. J. (1994). TQM self-assessment in the UK. The TQM Magazine, 6(4), 5661.

Flick, U. (2006). An introduction to qualitative research. London: Sage Publications.

Garengo, P., \& Biazzo, S. (2012). Unveiling strategy in SMEs through balanced scorecard implementation: A circular methodology. Total Quality Management \& Business Excellence, 23(1), 79-102.

Ghobadian, A., \& Gallear, D. (1997). TQM and organization size. International Journal of Operations \& Production Management, 17(2), 121-163.

Hansson, J., \& Klefsjö, B. (2003). A core value model for implementing total quality management in small organisations. The TQM Magazine, 15(2), 71-81.

Hargadon, A. B., \& Eisenhardt, K. M. (2000). Speed and quality in new product development: An Emergent Perspective on Continuous Organizational Adaptation. In R. E. Cole \& R. W. Scott (Eds.), The Quality Movement \& Organization Theory (pp. 331-346). London: Sage Publications.

Hellsten, U. (1997). The springboard. A TQM-based tool for self-assessment. Licentiate thesis. Luleå: Division of Quality Technology \& Statistics. Luleå University of Technology.

Jones, E. C., Parast, M. M., \& Adams, S. G. (2010). A framework for effective Six Sigma implementation. Total Quality Management \& Business Excellence, 21(4), 415-424. 
Kotter, J. P. (1995). Leading Change: Why Transformation Efforts Fail. Harvard Business Review, 73(2), 59-67.

Kumar, M., Antony, J., \& Tiwari, M. K. (2011). Six Sigma implementation framework for SMEs - a roadmap to manage and sustain the change. International Journal of Production Research, 49(18), 5449-5467.

Liker, J. K. (2004). The Toyota way : 14 management principles from the world's greatest manufacturer. New York: McGraw-Hill.

Oakland, J. S., \& Tanner, S. (2007). Successful Change Management. Total Quality Management \& Business Excellence, 18(1-2), 1-19.

Palmer, I., Dunford, R., \& Akin, G. (2009). Managing organizational change: a multiple perspectives approach (2nd ed. Vol. 28): McGraw-Hill/Irwin.

Pettigrew, A. M. (1987). Context and Action in the Transformation of the Firm. Journal of Management Studies, 24(6), 649-670.

Prajogo, D., \& Brown, A. (2006). Approaches to adopting quality in SMEs and the impact on quality management practices and performance. Total Quality Management \& Business Excellence, 17(5), 555-566.

Rahman, M. N. A., \& Tannock, J. D. T. (2005). TQM Best Practices: Experiences of Malaysian SMEs. Total Quality Management \& Business Excellence, 16(4), 491-503.

Schroeder, R. G., Linderman, K., Liedtke, C., \& Choo, A. S. (2008). Six Sigma: Definition and underlying theory. Journal of Operations Management, 26(4), 536-554.

Shah, R., \& Ward, P. T. (2003). Lean manufacturing: context, practice bundles, and performance. Journal of Operations Management, 21(2), 129-149.

Spear, S., \& Bowen, H. K. (1999). Decoding the DNA of the Toyota Production System. Harvard Business Review, 77(5), 96-106.

Upton, D. (1996). Mechanisms for building and sustaining operations improvement. European Management Journal, 14(3), 215-228.

van der Wiele, A., Williams, A. R. T., Dale, B. G., Carter, G., Kolb, F., Luzon, D. M., . . . Wallace, M. (1996). Self-assessment. A study of progress in Europe's leading organizations in quality management practices. International Journal of Quality and Reliability Management, 13(1), 84-104.

Wilkes, N., \& Dale, B. G. (1998). Attitudes to self-assessment and Quality Awards: a study in small and medium-sized companies. Total Quality Management, 9(8), 731-139.

Yin, R. K. (1994). Case study research. Design and methods (2 ed.). Thousand Oaks, California: Sage Publications.

Yusof, S. R. M., \& Aspinwall, E. (2000a). A conceptual framework for TQM implementation for SMEs. The TQM Magazine, 12(1), 31-37.

Yusof, S. R. M., \& Aspinwall, E. (2000b). Total quality management implementation frameworks: comparison and review. Total Quality Management, 11(3), 281-294. 